\title{
Direito Natural Feyerabend (Curso de Direito Natural (1784), segundo as anotações do aluno Gottfried Feyerabend)
}

\author{
IMMANUEL KANT
}

\section{Introduçãa ${ }^{1}$}

/ xxvii,13192/

A natureza inteira está submetida à vontade do ser humano até onde o poder deste alcance, excetuados outros seres humanos e racionais. Consideradas pela razão, as coisas na natureza só podem ser vistas como meios para fins, mas apenas o ser humano pode ser visto como um fim mesmo. Não posso pensar nenhum valor, relativamente a outras coisas, a não ser que as considere como meios para outros fins. Por exemplo: a lua tem valor para nós na medida em que ilumina a terra, engendra as marés etc. A existência das coisas irracionais não tem nenhum valor se não há alguém que possa delas servir-se, i.e. se nenhum ser racional as utiliza como meios. Também os animais não têm em si qualquer valor, já que não são conscientes de sua existência - o ser humano é, portanto, o fim da criação; ele pode também, contudo, ser utilizado como meio por um outro ser racional, mas não é nunca mero meio, e sim ao mesmo tempo fim. Por exemplo: se o pedreiro me serve como meio para a construção de uma casa, eu lhe sirvo ao mesmo tempo como meio para conseguir dinheiro. Pope, em seu Ensaio

1. Como dito na apresentação, esta tradução foi feita no contexto do Grupo de Traduções Kantianas, ligado ao Grupo de Filosofia Alemã, da USP. Agradeço a todos pelas sugestões, e à Monique Hulshof pela minuciosa e enriquecedora revisão. Agradeço ainda a Frederick Rauscher, da Universidade de Michigan, por nos ter passado a sua tradução provisória do Naturrecht Feyerabend para o inglês, tradução esta que foi de grande utilidade e à qual faço menção em outras notas. (N. do T.)

2. A numeração indicada entre barras corresponde à paginação da edição da Academia: volume xxvii, pp. 1319-29. (N. do T.) 
sobre o homem, fala sobre o ganso: "o ser humano também me serve, pois ele me dá a comida”. No mundo como sistema de fins tem de haver afinal um fim, e este fim é o ser racional. Se não houvesse um fim, também os meios seriam vãos e não teriam qualquer valor. - O ser humano é fim e, por isso, seria contraditório que ele devesse ser um mero meio. - Se faço um contrato com um empregado, então ele também tem de ser fim como eu, e não mero meio. Ele também tem de querer. - A vontade humana é limitada, portanto, à condição do consentimento geral da vontade de outrem. - Se deve haver um sistema de fins, então o fim e a vontade de um ser racional têm de colocar-se de acordo com a do outro. A vontade do ser humano não é limitada por nada na natureza a não ser pelas vontades dos demais seres humanos. ${ }^{3}$ - Pois todo ser humano é ele mesmo fim e, por isso, não pode ser mero meio. Eu não posso tirar algo da terra de alguém para com isso adubar a minha própria; pois neste caso o outro seria um mero meio. Essa limitação se baseia nas condições do consentimento mais geral possível da vontade de outrem. Não há nada, além do ser humano, a que se possa atribuir tanto respeito quanto ao direito humano. - O ser humano é, assim, um fim em si mesmo, e só pode ter, portanto, um valor interno, i.e. uma dignidade, em cujo lugar não pode ser posto nenhum equivalente. Outras coisas têm um valor externo, i.e. um preço contra o qual alguma coisa que sirva para o mesmo fim possa ser posta como equivalente. $O$ valor interno do ser humano baseia-se em sua liberdade, no fato de que ele tem uma vontade própria. Já que ele deve ser o fim último; então sua vontade não tem de depender de mais nada. - Os animais têm / xxvii,1320 / uma vontade, mas não a sua própria vontade, e sim a vontade da natureza. A liberdade do ser humano é a condição sob a qual o ser humano pode ser ele mesmo um fim. As outras coisas não têm qualquer vontade, mas devem, isto sim, guiar-se

3. Em alemão, essa frase tem uma oração que não parece fazer sentido: "Der Wille des Menschen wird durch die ganze Natur nicht eingeschränkt, obwohl das Vermögen, ausgenommen durch Willen andrer Menschen”. Optamos por omiti-la do texto, tal como fez Rauscher em sua tradução provisória. Como o texto é constituído por anotações manuscritas, é compreensível que haja passagens incompletas ou sem sentido. 
pela vontade alheia, deixar-se utilizar como meios. Se o ser humano deve, portanto, ser um fim; então ele tem de ter uma vontade própria, pois não pode deixar-se utilizar como meio. O direito é a limitação da liberdade pela qual ela pode coexistir com toda outra liberdade segundo uma regra universal. Suponhamos que alguém gosta de um lugar no qual um outro se encontra, e quer expulsá-lo daí. Eu posso sentar-me onde quiser, e ele onde quiser também. Se ele, porém, está sentado; então eu não posso sentar-me ao mesmo tempo: por isso tem de haver uma regra universal sob a qual a liberdade de ambos possa coexistir. Eu prometo algo a ele, portanto, e ele é de fato meio, mas também fim. Não é necessária a limitação da liberdade? E pode a liberdade limitar-se de outro modo que não por si mesma segundo regras universais, de modo a poder existir consigo mesma? Se os seres humanos não fossem livres, sua vontade seria regulada por leis universais. Se cada um, porém, fosse livre sem leis, então nada mais terrível poderia ser pensado. Pois cada um faria com o outro o que quisesse, e assim ninguém seria livre. Os mais selvagens animais seriam menos temidos do que um homem sem lei. Daí que Robinson Crusoé se tenha assustado tanto ao ver, depois de alguns anos, as pegadas de um homem em sua ilha deserta, passando a viver sem sossego e a atravessar as noites em claro. - Daí também que os marinheiros não hesitem em atirar e matar imediatamente os selvagens de uma ilha desconhecida, pois não sabem o que esperar deles. - Veja-se também a morte na Nova Zelândia do cavaleiro Marion, que viveu um mês em plena amizade com os selvagens, sem nada lhes fazer de mal, mas acabou devorado por eles, juntamente com 22 marinheiros, apenas porque desejavam comê-lo. -

Pois o animal se guia por seu instinto, que tem regras. Mas de um tal ser humano eu não sei minimamente o que esperar. Sparman, em sua Viagem ao Cabo da Boa Esperança, conta que os leões não caçam a sua presa, mas a seguem sorrateiramente e, quando acreditam estar perto o suficiente, dão um salto súbito e, se mesmo assim sua vítima lhes escapa, voltam atrás, como se quisessem ver onde erraram, e então se esgueiram. Os seres humanos o sabem, e podem orientar-se por isso. Assim, um hotentote seguia certa vez para casa, e um leão o seguia sorrateiramente há 
algum tempo. Ele sabia, pois, que não poderia chegar em casa antes do anoitecer, e que o leão o devoraria num piscar de olhos. Ele tirou então as suas roupas e colocou-as numa vara, de modo a parecer que estava ali parado. Ele próprio, porém, cavou um buraco no morro e nele se escondeu. O leão se aproximou furtivamente, deu um salto repentino e, como a vara cedesse rapidamente, precipitou-se com ela morro abaixo e se esgueirou. Quando está com muita fome, porém, o leão também caça a presa.

\section{/ xxvii,1321 /}

A liberdade tem, portanto, de ser limitada, mas não pode ser pelas leis da natureza; pois então o ser humano não seria livre; logo, ele tem de limitar-se a si mesmo. O direito se baseia, portanto, na limitação da liberdade. Ele é mais fácil de explicar do que o dever. - No direito a felicidade não é levada em conta; pois cada um pode tentar alcançá-la como quiser.

Ainda não se conseguiu determinar, a partir de princípios, o lugar do jure naturae [direito natural] na filosofia prática, nem tampouco mostrar a fronteira entre ele e a moral. Por isso as diferentes proposições de ambas as ciências acabam por misturarse. - Para desfazer a confusão, portanto, deve-se tentar explicitar os conceitos do direito. Queremos tentar fazer de maneira mais metódica, agora, aquilo que na última aula fizemos de maneira tumultuada.

Que tenha de haver alguma coisa como um fim em si mesmo, e que nem todas as coisas possam existir meramente como meios, é tão necessário num sistema de fins quanto um Ens a se [ser em si] na série de causas eficientes. Uma coisa que é em si mesma um fim é um Bonum a se [bem em si]. O que pode ser considerado meramente como meio tem valor como meio apenas se é utilizado como tal. Para isso, então, tem de existir um ser que seja fim em si mesmo. Uma coisa na natureza é um meio para outra; isso continua indefinidamente, e é necessário, ao final, pensar uma coisa que seja ela própria um fim, pois do contrário a série não teria um término. 
$\mathrm{Na}$ série das causas eficientes há um ens ab alio [ser dependente de outro], mas ao fim tenho de chegar a um ens a se [ser em si]. No querer, o fim é a razão pela qual existe o meio. Uma coisa é um meio para a outra, e por isso deve haver uma coisa, ao final, que não seja mais meio, mas um fim em si mesmo. Como pode, porém, existir um ser que seja em si mesmo um fim, e nunca meio, é tão incompreensível quanto o modo pelo qual de existir um ser necessário na série das causas. Ainda assim, temos de admitir ambos devido à necessidade de nossa razão de ter tudo completo. Reside na própria natureza da razão humana que ela nunca possa discernir algo que não seja condicionado, nem algo sem fundamento, e no caso do ens [ser] e bonum a se [bem em si] não há nenhum fundamento além dela. Eu digo que o homem existe para ser feliz. Por que, no entanto, tem valor o ser feliz? Ele só tem um valor condicionado, a saber, porque a existência do homem tem um valor. Por que, então, tem valor a existência? Porque Deus a quis. Pois em si mesma ela não tem qualquer valor. Mas eu posso também perguntar: por que tem valor a existência de um Deus?

O ser humano é um fim em si mesmo, e nunca mero meio; isso é contra a sua natureza. Se alguém confiou uma quantia a mim e quer tê-la de volta, e eu não devolvo e digo que posso utilizá-la melhor do que ele com vistas a melhorar o mundo, então estou utilizando o seu dinheiro e a ele mesmo como meios. Se ele deve ser um fim; então sua vontade tem, como eu, de ter um fim.

Se apenas seres racionais podem ser um fim em si mesmo, eles não podem sê-lo porque têm razão, mas sim porque têm liberdade. A razão é tão somente um meio. - $\mathrm{O}$ ser humano poderia produzir através da razão, sem / xxvii,1322 / liberdade e segundo as leis universais da natureza, aquilo que o animal consegue por meio do instinto. - Sem a razão um ser não pode ser fim em si mesmo; pois ele não pode ser consciente de sua existência, não pode refletir sobre isso. Mas a razão não constitui ainda uma causa: se o homem é um fim em si mesmo, ele tem uma dignidade que não pode ser substituída por nenhum equivalente. Não é a razão, porém, que nos dá dignidade. Pois nós vemos que a natureza realiza com os animais, por meio do instinto, aquilo que a razão só escolhe depois de muitos rodeios. A natureza poderia, portanto, 
ter organizado nossa razão, segundo leis da natureza, de tal modo que o ser humano pudesse aprender a ler por si mesmo, inventar diversas artes, e tudo isso segundo determinadas regras. Neste caso, porém, nós não seríamos melhores do que os animais. Mas a liberdade, a liberdade apenas, faz com que sejamos um fim em si mesmo. Aqui temos a faculdade de agir segundo nossa própria vontade. Se a nossa razão fosse regulada por leis universais, minha vontade não seria minha própria, mas a vontade da natureza. - Se as ações do ser humano repousassem no mecanismo da natureza, o fundamento delas não estaria nele mesmo, mas fora dele. - Eu tenho de pressupor a liberdade do ser se ele deve ser um fim perante si mesmo. Um tal ser tem de ter liberdade da vontade. Como posso compreendê-la não sei; trata-se de uma hipótese necessária, contudo, se devo pensar os seres racionais como fins em si mesmos. Se ele não for livre, então ele está nas mãos de um outro, é sempre o fim de um outro, portanto mero meio. A liberdade não é apenas, portanto, a mais elevada condição, mas também a condição suficiente. Um ser que age livremente tem de ter razão; pois do contrário eu seria apenas afetado pelos sentidos, seria por eles regido. Sob qual condição pode um ser livre ser fim em si mesmo? Quando a liberdade for ela mesma uma lei. Ele tem de ser considerado sempre como fim, jamais como meio. As leis são ou leis da natureza, ou leis da liberdade. Se deve encontrar-se sob leis, a liberdade tem de dar leis a si mesma.

Se ela extraísse as leis da natureza, ela não seria livre. - Como pode a liberdade ser ela mesma uma lei? Sem leis não pode ser pensada nenhuma causa e, portanto, nenhuma vontade, pois só existe causa quando algo dela se segue segundo uma regra constante. Se a liberdade estiver submetida a uma lei da natureza, então ela não é liberdade. Ela tem, portanto, de ser ela mesma lei. Parece difícil compreender isso, e todos os professores de direito natural erraram quanto a este ponto, o qual nunca sequer descobriram. Todas as leis da vontade são práticas e expressam uma necessidade que é ou objetiva, ou subjetiva. São, portanto, leis objetivas e subjetivas da vontade. As primeiras são regras de uma vontade em si boa, de como esta deveria proceder, e as outras são regras segundo as quais uma dada vontade efetivamente procede. - As regras subjetivas da 
vontade são muito diferentes das objetivas. $\mathrm{O}$ ser humano sabe que não deve comer aquilo que lhe é nocivo. Isto é uma regra objetiva. Se ele, no entanto, deixa-se levar pela sensibilidade e come, ele está agindo segundo regras subjetivas da vontade.

/ xxvii,1323 / Se a vontade de um ser é boa em si mesma; então as leis objetivas de sua vontade não se diferenciam das subjetivas. - A vontade do ser humano não é do tipo em que os fundamentos subjetivos do querer concordam com os objetivos. Por isso a regra objetiva do querer, aplicada a uma vontade cujas regras subjetivas não concordam com as objetivas, é denominada imperativo. Para seres cuja vontade já é em si boa não vale nenhuma regra como imperativo. Uma lei é um imperativo quando, por meio da ideia de uma vontade em si boa, necessita uma vontade que não é em si boa pressupondo uma vontade que não o seria de bom grado e que, portanto, teria de ser necessitada, tornada necessária. Tratase aqui da necessitação em que o contingente tem de ser tornado necessário. O ser humano pode escolher o bem e o mal e, portanto, a vontade boa, no seu caso, é uma vontade contingente. No caso de Deus, a sua vontade não é contingente; por isso também não há, para ele, uma lei imperativa voltada a necessitar a sua vontade. Pois isto seria supérfluo. A necessitação de uma ação em si contingente por meio de fundamentos objetivos é uma necessitação (Necessitatio) prática que se diferencia da necessidade (Necessität) prática. Também há leis em Deus, mas elas têm necessidade (Notwendigkeit) prática. - Uma necessitação prática é imperativa, é um comando (Gebot). Se a vontade é em si mesma boa, não se pode comandar-lhe de modo algum. Por isso não há qualquer comando em Deus. Em Deus, a necessidade prática objetiva é também necessidade prática subjetiva. Coerção é a necessitação para ações indesejadas. Para isso tem de haver um móbil como contraposição. As leis práticas, portanto, também podem ser coerção, mesmo que o ser humano faça algo a contragosto; ele tem mesmo de fazê-lo. "Eu devo fazer isso" significa que uma ação necessária seria boa se praticada por mim. Disso não se segue ainda que eu o farei: pois eu tenho também razões subjetivas contrárias. Mas eu me represento aquilo como necessário. Os comandos servem, portanto, para uma vontade imperfeita. As leis práticas, enquan- 
to fundamentos que tornam necessária a ação, são denominadas imperativos. Não se encontra nenhuma virtude no ser humano para a qual não se possa encontrar um grau de tentação capaz de comprometê-la. Daí que o pedido "não nos deixe cair em tentação" seja um pensamento glorioso. Nós temos 3 imperativos: os técnicos, os pragmáticos e os morais; regras da habilidade, da prudência e da sabedoria. Imperativos que comandam algo sob a condição de um querer possível, como simples meio para um fim meramente possível e agradável, são imperativos da habilidade. São saberes práticos. Por exemplo: você deve fazer um corte transversal sobre uma linha. Isso não é um imperativo para todos, mas apenas sob a condição de que se queira atingir um mero fim possível (a divisão de uma linha em duas partes iguais). Ele é bom, portanto, enquanto meio para um mero fim possível. São imperativos da técnica, da habilidade. Nós aprendemos primeiro a habilidade e os meios para fins, sem saber ou supor que precisaremos dos fins. Por isso os pais não perguntam muito se o seu filho está moralmente educado, mas se aprendeu muito. A natureza forneceu o impulso para conservar os homens. Pois não sei se / xxvii,1324 / não chegarei ao momento em que precisarei fazer uso disso. Os imperativos da habilidade são meramente condicionados e comandam sob a condição de um fim apenas contingente e possível. 2) Os imperativos da prudência são aqueles que prescrevem os meios para o fim universal a que se remetem, no ser humano, todos os fundamentos subjetivos do querer, i.e. a felicidade de que carecem todas as criaturas. Aqui os imperativos comandam sob a condição de um fim efetivo. 3) O imperativo da sabedoria comanda a ação como o fim mesmo. A regra "não mentir" pode ser a habilidade e o meio para enganar a outrem. Ela pode ser prudência, pois posso atingir todos os meus propósitos por meio dela. Eu serei tido por honesto, confiável, bem reputado etc. Mas também posso compreender essa regra como sabedoria. Neste caso, não a considero como meio para meu fim. - Pode acontecer comigo o que for, bom ou ruim, isso não me importa. Ela segue sendo uma lei. Mesmo que eu não consiga executá-la, ela permanece venerável para mim. - Consideramos esse bem incondicionado muito mais elevado para nós do que tudo o que pudéssemos atingir por meio da ação ao utilizá-la como mero 
meio. - A boa ação tem muito mais valor em si do que o bem alcançado pelo seu praticante; por exemplo, que o amassem por isso etc. - Não são as boas consequências que determinam o valor. A virtude tem em si uma dignidade que independe até mesmo de ela poder ser praticada; as boas consequências têm valores que podem ser substituídos por um equivalente. Todos os imperativos são condicionados ou incondicionados, e os condicionados são ou problemáticos, imperativos da habilidade, ou assertóricos, imperativos da prudência. $\mathrm{O}$ imperativo incondicionado da sabedoria é apodítico, todos os imperativos são, portanto, hipotéticos ou categóricos. Deve-se falar a verdade: isto é inteiramente incondicionado. Como é possível um tal imperativo categórico? Imperativos categóricos comandam sem condições empíricas. Eles podem perfeitamente ter condições, mas condições a priori, e então a própria condição é categórica. Todos os fins que se queiram remetem, em última instância, à felicidade. Esta é a soma do alcance de todos os fins. A felicidade é, no entanto, uma condição empírica: pois não posso saber se algo contribuirá para minha felicidade, nem como serei feliz; mas tenho antes, isto sim, de fazer a experiência. - Os imperativos da prudência são pragmáticos. As leis são denominadas sanções pragmáticas que visam o maior bem comum. A história pragmática é a história que nos torna prudentes. É pragmático tudo aquilo que serve à promoção da felicidade. Os imperativos categóricos se diferenciam dos morais. Os imperativos pragmáticos estão no fundamento dos imperativos da habilidade, pois eu só aprendo algo com estes por acreditar que esse algo poderá contribuir para a minha felicidade se eu puder depois pensar o que ele seja. A felicidade não é, portanto, um princípio moral. Eu não posso fornecer a priori regras da felicidade? Não. Eu posso certamente conceber a felicidade que está ligada a uma coisa, mas não conceber a priori em que consiste tal felicidade. Pois o agradável não é um conceito, mas sim / xxvii,1325 / a sensação de como sou afetado pela coisa. Por isso não posso ter qualquer regra a priori $\mathrm{da}$ felicidade, já que não conheço nenhum caso in concreto [concretamente]. O imperativo pragmático repousa, portanto, em condições meramente empíricas. Shaftesbury diz que a felicidade não daria à moral qualquer valor. Para, pois, dar valor à moralidade, 
teríamos de pressupor que o ser humano tem na ação uma satisfação e uma insatisfação imediatas. A isso ele chamava sentimento moral. As ações não teriam nenhum valor se apenas sinto prazer nas suas consequências, pois neste caso elas teriam valor apenas como meio; como também Hutcheson diz. Desse modo, porém, o imperativo moral não é categórico, pois se pressupõe que só tem valor, nas suas ações morais, o ser com quem esse sentimento é partilhado. Pois um tal sentimento não pode ser exibido a priori, mas apenas a partir da experiência. O que a experiência nos ensina é contingente: nós não poderíamos discernir a priori a necessidade desse sentimento. $\mathrm{O}$ valor das ações morais estaria apenas naquele que tem um sentimento moral, e dependeria do ser supremo nos dar um tal sentimento, de modo que as ações morais não seriam em si mesmas boas ou más.

Existe sem dúvida um tal sentimento moral nos seres humanos, mas ele não precede o conhecimento das regras morais nem as torna possíveis, mas antes se segue delas. Se o sentimento moral dos seres humanos fosse a razão pela qual as ações podem ser reconhecidas ou como boas ou como más, então esses sentimentos poderiam apresentar-se em diferentes graus. E como o sentimento moral não é mais forte do que os demais sentimentos, nem isso poderia ser provado, acontece o mesmo que com os sentimentos físicos, podendo o ser humano escolher, dentre os sentimentos, aquele que lhe parece mais satisfatório. $\mathrm{E}$ isso independe da origem do sentimento. Tudo nos estimula. Os sentimentos são distintos apenas segundo a intensidade, e iguais segundo a espécie. As leis morais comandam, porém, de tal maneira que nenhum instinto ou sentimento prevaleça. Então o sentimento moral teria de ser o mais intenso, mas este não é o caso. Seria um tolo o ser humano que preferisse seguir um sentimento menor em detrimento de um maior. Se o sentimento moral fosse o maior, todos seriam virtuosos. Se a virtude me agradasse acima de tudo quando a represento a priori, eu desejaria ter um sentimento que me conduzisse a ela com a maior força; o agradável repousa sobre a aprovação da doutrina pela qual, se a virtude estivesse para mim acima de todos os prazeres, eu gostaria de ser sempre virtuoso. As leis morais são sempre categóricas e têm obrigatoriedade, i.e. 
necessitação moral a uma ação. A ação a que sou necessitado pelas leis morais é o dever. Uma lei moral vem antes. Se a vontade é boa em si mesma, a lei moral não precisa de obrigatoriedade. Se ela não o é, tem de ser necessitada. A moral não pode originar-se da inclinação, isto é sabido pelo entendimento comum. Todos os seres humanos têm inclinação à vida. Se alguém fica doente, busca todas as ajudas possíveis: ele o faz por inclinação. Se alguém, no entanto, é infeliz em sua vida e fica doente, mas / xxvii,1326 / ainda assim cuida de sua saúde, então ele certamente não o faz por inclinação, mas por dever. Neste último caso há um conteúdo moral. Se um homem se casa com uma bela mulher, ele a amará por inclinação. Se ele ainda a ama, porém, depois que o tempo a deixou enrugada, isto é algo que ele faz por dever. Uma ação moral não tem valor quando se origina da inclinação, mas apenas quando se origina do dever. Uma ação pode ser conforme ao dever, mas não ter acontecido pelo dever. Nós temos de praticar as ações morais sem um mínimo de móbil, apenas por dever e respeito pela lei moral. A lei tem de determinar por si mesma a vontade. Se acontecem por dever, as ações têm então, e somente então, um valor moral. Apenas a conformidade universal a leis pode obrigar-me. Se cada qual não mantivesse suas promessas, e isto fosse uma regra universal, esta não poderia valer como lei universal, pois ninguém prometeria nada sabendo que não iria cumprir e que os outros também o saberiam.

Obrigatoriedade é a necessitação moral da ação, i.e. a dependência de uma vontade em si boa relativamente ao princípio da autonomia, ou as leis práticas objetivamente necessárias. Dever é a necessidade objetiva da ação a partir da obrigatoriedade. Respeito é a estima por um valor que limite todas as inclinações. Nós respeitamos alguém quando o estimamos tanto que limitamos nosso amor próprio etc. Nós o estimamos mais do que a nós mesmos. As ações não devem ocorrer com base na necessidade das inclinações. Se uma ação ocorre por medo, ela também não é dever. O valor tem de repousar, portanto, no próprio dever. Todas as leis podem necessitar a vontade ou por meio de sua conformidade a leis, ou por meio dos móbiles a ela vinculados, ou ainda por meio da coerção e do medo. Quando necessita por meio da inclinação e do medo, 
a lei não o faz por si mesma, mas de maneira condicionada: a lei que necessita em si mesma tem de necessitar através do respeito. No respeito eu deixo de lado a minha inclinação e dou um valor absoluto à ação. Nosso autor e outros falam de obligatio per poenas [obrigação através de penas], como também Baumgarten. Mas obrigar alguém através de poenas [penas] e praemia [incentivos] é uma contradictio in adjecto [contradição em termos]; pois então eu o levo a ações que ele pratica não por obrigatoriedade, mas por medo e inclinação. Eu também posso, desse modo, forçá-lo a coisas que não são sequer obrigatórias para ele. Mas como pode uma lei ser respeitada por si mesma e também por isso necessitar? Deus não tem respeito pela lei porque não tem nenhuma inclinação que pudesse limitar o respeito. $\mathrm{O}$ respeito é algo que necessita, mas em Deus não pode haver nada que obrigue. Um ser racional como fim em si mesmo tem de ter sua própria vontade e, portanto, tal vontade tem de ser livre. A vontade humana, enquanto livre, não pode ser determinada por móbiles, pois então não seria livre, mas igual aos animais. Seria determinada pela natureza. Uma vez que nenhum móbile a determine, e dado que ela não pode existir sem leis, então a lei, enquanto lei apenas, tem de determiná-la. Assim, a forma da lei tem de determinar a vontade, e esta, portanto, precisa ter respeito pela lei. Quando me pergunto se devo / xxvii,1327 / devolver a alguém o depósito que este alguém confiou apenas a mim: se apenas a minha inclinação me determinasse, eu o conservaria comigo. No entanto, a vontade é livre e, portanto, precisa ter uma lei. A lei está dada: "você deve devolver o depósito". Tirarei algum proveito disso? Não. Devo temer que isso seja descoberto? Suponhamos que o outro esteja morto e eu possa negar tudo. Se eu transformasse numa regra universal que cada qual pode conservar o depósito se lhe aprouver, isto não poderia jamais tornar-se numa lei universal, pois então ninguém confiaria nada em depósito a ninguém. Se minha vontade não deve ser desenfreada, mas ter leis, então elas têm de ser assim. O respeito pela lei se baseia em que essa é a única possibilidade pela qual a ação pode estar submetida a leis universais. - Pagar a dívida é um dever. A obrigatoriedade é a relação com a lei, neste caso com o contrato. A legalidade é a concordância da ação com o dever, sem levar em conta se este 
é ou não o seu fundamento de determinação. A moralidade é a concordância da ação com o dever na medida em que este seja o seu fundamento de determinação. Em todas as ações jurídicas, a legalidade é conformidade ao dever, mas não moralidade, pois elas não ocorrem por dever. $\mathrm{Na}$ legalidade só importa se eu ajo de acordo com o dever, sendo indiferente se o faço por respeito ou inclinação e medo. Se, contudo, não observo a lei por respeito à lei, minhas ações não são morais. A maior parte das ações humanas conformes ao dever é legal, em especial aquelas que podem ser coagidas sem o uso da violência. É legal quando sano minha dívida no tempo pertinente. Se sei que o credor é um homem pontual, faço-o por medo. Se ele fosse condescendente, eu talvez seguisse hesitando em pagar. A ética é a ciência do julgamento e determinação das ações segundo sua moralidade. O jus [direito] é a ciência do julgamento das ações segundo sua legalidade. A ética também é denominada doutrina da virtude. $\mathrm{O}$ jus pode tratar de ações que sejam coagidas a isso. Pois lhe é indiferente se as ações acontecem por respeito, medo, coerção ou inclinação. A ética não trata de ações que podem ser coagidas; a ética é a filosofia prática da ação tendo em vista a disposição. O jus é a filosofia prática das ações que não leva em conta a disposição. Tudo que tem obrigatoriedade, portanto todos os deveres, pertencem à ética. $\mathrm{O}$ jus trata de deveres e ações que são conformes à lei e podem ser coagidos. A ação é dita justa quando concorda com a lei, virtuosa quando se origina do respeito pela lei. Um ação pode, portanto, ser justa sem ser virtuosa. A disposição de agir por dever, por respeito à lei, constitui a virtude. A ética contém a doutrina da virtude, o jus a doutrina do direito. Mesmo que a ação seja também conforme à coerção, ela pode ser conforme à lei. Diz-se que o direito é uma doutrina dos deveres que podem e devem ser cumpridos por meio da força: mas isto se baseia no seguinte. Dever é necessitação, portanto deve ser necessário independentemente do respeito pela lei e tem de acontecer, pois, por meio da coerção. Fora a coerção e o respeito, nada necessita a uma ação. A coerção / xxvii,1328 / é limitação da liberdade. Uma ação é correta (recht) quando concorda com a lei, justa (gerecht) quando concorda com as leis da coerção, i.e.: com as doutrinas do direito. Chama-se correto, em 
geral, àquilo que concorda com uma regra. Por isso se chama linea recta [linha reta] à linha que corre paralela à régua, a qual é chamada de regra. O correto é, portanto, ou virtuoso ou justo. Quando é uma ação conforme à coerção? Uma ação que se pauta pela regra universal da liberdade é correta; se ela contradiz a liberdade segundo uma regra universal, então ela é injusta. A intenção pode ser aqui a que for. Minha ação deveria apenas ser concebida de modo a conformar-se à liberdade universal. Não posso roubar nada de alguém, mas também não tenho de dar-lhe nada. Não ajo injustamente, portanto, se vejo alguém morrer e não lhe ajudo. Esta é uma actio justa [ação justa]. A ação é externamente correta, embora internamente não. Eu apenas não quero roubar a felicidade de alguém, além disso nada me importa: ele pode tentar ser feliz como quiser. É correta uma ação que se opõe à ação que, por seu turno, vai contra a liberdade universal. O opor-se a uma ação incorreta é um obstáculo à ação que se opõe à liberdade universal, portanto é uma promoção da liberdade e da concordância da liberdade privada com a liberdade universal. A oposição à ação da liberdade de um outro é denominada coerção. A concordância da liberdade privada com a liberdade universal é o princípio supremo do direito, o qual é uma lei de coerção.

Nosso autor, juntamente com outros, define o direito sem uma ciência das leis a cujo cumprimento se pode ser coagido e cuja coerção não contradiz o dever. A coerção é conforme ao direito quando promove a liberdade universal. Uma lei das ações a que se pode coagir alguém é uma lei de coerção, e o direito a coagir é um direito de coerção. Um direito que não seja de coerção é a equidade. Esta é um jus late dictum [em sentido amplo], aquele é um jus stricte dictum [em sentido estrito]. A equidade é o direito sem coerção. A obrigação de observar uma lei a que não se pode ser coagido é uma obrigação livre de coerção. Eu posso ser coagido a tudo aquilo que é necessário para a conservação da liberdade universal. A equidade é um direito ético. Se posso exigir algo de alguém pelo direito em sentido estrito, então eu posso coagi-lo caso ele se recuse a isso; se posso exigir apenas por equidade, então é uma obrigação que ele tem comigo à qual, no entanto, não posso 
coagi-lo. A ação que concorda com a lei universal na disposição manifesta, mas não na interna, não é equitativa. Trata-se de um direito imperfeito, e não de um direito perfeito ou em sentido estrito, no qual eu posso ser coagido. É imperfeito, mas ainda assim um direito. Minha liberdade concorda com a do outro quando concorda desse modo. Supondo que eu tenha acertado com meu empregado de pagar-lhe 20 Rthl. (Reichsthalers) ${ }^{4}$ por ano, e as coisas tenham encarecido a ponto de ele não poder sobreviver com esse dinheiro, não pratico uma injustiça contra ele / xxvii,1329 / se, mesmo frente a seus apelos por mais, pagar apenas as 20 Rthl., pois estou agindo de acordo com as disposições por ele manifestas. Mas eu não agi de maneira equitativa, pois ele acreditava que os 20 Rthl. seriam suficientes para ele passar o ano, na medida em que os preços continuassem modestos. Eu podia pressupor a sua intenção. Ele tinha, portanto, um direito efetivo, mas não coercitivo, pois as disposições, posto serem internas, não poderiam ser submetidas à coerção. $\mathrm{O}$ equitativo pode ser denominado eticamente justo.

Aqui não trataremos da equidade, mas apenas do direito estrito. Os juristas se equivocam com frequência, ao coagir à equidade. A ética contém deveres do direito em sentido forte e da equidade. $\mathrm{O}$ direito diz respeito à liberdade, a equidade à intenção. Se não promovo a felicidade de alguém, não causo com isso nenhum prejuízo à sua liberdade, mas o deixo fazer o que queira. A liberdade tem de concordar com a universalidade. Se isso não ocorre, pode-se coagir aquele que obstrui a liberdade. A causa do direito, aqui, não é nem a felicidade nem o comando dos deveres, mas a liberdade. O autor estabeleceu em seus Prolegomena que haveria uma lei divina e que nós seríamos felizes por meio dela; isso não será aqui necessário. Seus Prolegomena parecem ter feito parte de uma preparação para um Collegii [curso] específico.

Tradução de Fernando Costa Mattos

4. Moeda corrente na Prússia da época. 